\title{
O 31 PANORAMA DA ARTE BRASILEIRA COMO MONTAGEM EM WARBURG
}

Karoline Marianne Barreto

\section{RESUMO}

Esta pesquisa busca maneiras diferentes para se pensar curadoria em arte contemporânea. A principal proposição que se guiou o pensamento nesta pesquisa foi o princípio de montagem investigado por Warburg e que teve como principal resultado o Atlas Mnemosine. Esta montagem, presente em várias conferências, escritos e no Atlas proposto por Warburg na década de 20, neste estudo buscou-se aproximar suas ideias à arte contemporânea. Para tal aproximação, a escolha pela exposição $31^{\circ}$ Panorama da Arte Brasileira se deu pela maneira ímpar e eficaz de realizar a curadoria por Adriano Pedrosa.

Palavras Chave

Curadoria, montagem, Aby Warburg, panorama da Arte Brasileira.

\section{Abstract}

This research seeks different ways to think about curatorship in contemporary art. The main proposition that guided the thinking in this research was the principle composition investigated by Warburg and had as main result the Mnemosyne's Atlas. This composition, present at various conferences, written and Atlas proposed by Warburg in the 20s, this study sought to bring his ideas to contemporary art. For this approximation, the choice $b$ exhibition 31th Panorama of Brazilian Art was made by unique and effective way to accomplish curated by Adriano Pedrosa.

Key words

Curatorship, composition, Aby Warburg, panorama of Brazilian Art.

O objeto de pesquisa é a $31^{\text {a }}$ edição do Panorama da Arte Brasileira, realizada em 2009 no MAM-SP, com curadoria de Adriano Pedrosa. O objetivo é 
relacionar a exposição com alguns pensamentos e métodos construídos por Aby Warburg. Para tal pretensão, além de usar textos do autor, procurou-se textos de seus seguidores tratando de seu método, como Giorgio Agamben (Aby Warburg e a ciência sem nome) e Georges Didi-Huberman (La imagen superviviente).

Estes pensamentos de Warburg, que Giorgio Agamben define como a "ciência sem nome" ${ }^{1}$ vai além da história da arte, para algo mais amplo, em direção ao universal, sem se desvencilhar da imagem. O Atlas Mnemosine, uma de suas contribuições mais importantes, refere-se a pranchas enumeradas (até o número 79) contendo imagens de arte, mapas, cartas, cartazes, ilustrações de diferentes datas, ampliando metodologicamente qualquer fronteira temática e geográfica em torno de um tema abrangente, como astrologia, por exemplo.

Pensando a exposição como uma imagem, totalizante em si, e carregada de memória - fantasmas do passado - possivelmente podemos relacionar 0 questionamento de Pathosformel, problematizado por Warburg, e citado por Agamben:

(...) indissolúvel entrelaçamento de uma carga emotiva e de uma fórmula inconográfica, (...) pensamento que não pode jamais ser interpretado em termos de oposições superestimadas do tipo forma/ conteúdo, história dos estilos/história da cultura. AGAMBEN, p. 132-133

$\mathrm{Na}$ citação acima, o filósofo italiano afirma que quando pensarmos em Pathosformel, não devemos jamais pensar em um posicionamento excluindo o outro, ou é forma ou é conteúdo, sempre haverá o entrelaçamento, a memória não permite que a imagem seja apenas forma, apenas história da arte, por exemplo, sem levar em conta conteúdo e a história político-social.

\footnotetext{
${ }^{1} \mathrm{O}$ autor cita alguns nomes utilizados por Warburg na tentativa de nominar sua ciência durante sua vida: "história da cultura, psicologia da expressão humana, história da psique e iconologia do intervalo". AGAMBEN, Giorgio. Aby Warburg e a ciência sem nome. Tradução: Cezar Bartholomeu, In., Dossiê Warburg. Revista do Programa de Pós-Graduação em Artes Visuais - EBA/UFRJ: Rio de Janeiro, ano XVI, número 19, 2009. p.139 e 140.
} 
Tal conexão é central para que as imagens escolhidas possam ser pensadas em seus símbolos. Os símbolos, segundo Agamben, devem ser compreendidos em um nível intermediário entre a consciência e a identificação primitiva, de maneira que, seus significantes não sendo conscientes ou inconscientes, oferecem assim o intervalo correto para aproximação unitária da cultura além da oposição entre história (consciente) e antropologia (inconsciente) ${ }^{2}$.

Didi-Huberman ${ }^{3}$, pergunta de que estilo trata as combinações montadas por Warburg. Responde que são muitos estilos, marcados por contrastes e anacronismos, como exemplo, o autor cita de uma cultura a outra, um tempo a outro, inversões de orientação espacial, tendo como único denominador comum a escala das imagens, o que permitia a Warburg em suas conferências apresentá-las não uma a uma, senão todas juntas, sobre um mesmo significante. O símbolo compreendido por Warburg como alocado entre a consciência e a inconsciência - e seus significantes, alocados no mesmo espaço que o símbolo, oferece assim um intervalo onde esta imagem pode ser combinada com outras de épocas diferentes graças aos significantes em comum, por isso, o atlas pode ser pensado também como "uma nova teoria da função memorativa das imagens." 4

Outro pensamento importante de Warburg, explorado por Agamben e que é de interesse dessa pesquisa nos afirma que: em um horizonte mais vasto, as soluções estilísticas e formais adotadas pelos artistas (e também, no nosso caso, pelo curador) se apresentam como decisões éticas definindo a posição dos indivíduos e de uma época em relação à herança do passado, e a interpretação do problema histórico se torna, por isso mesmo, um diagnóstico do homem ocidental lutando para se curar de suas contradições e para encontrar, "entre o antigo e o novo, sua própria moradia vital." (AGAMBEN, p. 135)

\footnotetext{
${ }^{2}$ A aproximação da história e da antropologia através da cultura como núcleo central acontece 20 anos depois com Lévi-Strauss. AGAMBEN, op. cit.

${ }^{3}$ DIDI-HUBERMAN, Georges. La imagen superviviente. Historia del arte y tiempo de lós fantasmas según Aby Warburg. Trad. Juan Clatrava. Madrid: Abada Editores, 2009.

${ }^{4}$ Refere-se ao conceito de pathosformel formulado por Warburg. DIDI-HUBERMAN, na obra citada, trata deste conceito nas páginas 418 e 419 .
} 
De certa forma, é isso que o Adriano Pedrosa faz na $31^{\text {a }}$ edição do Panorama. Analisando a exposição como uma imagem construída à maneira do atlas mnemosine, podemos pensar sua construção como regida por decisões éticas em relação à herança do passado para encontrar seu lugar entre o antigo e o novo, usando como prática uma história da arte que, assim como aquela utilizada por Warburg, vai além das fronteiras geográficas e temáticas.

Sobre tal prática, ou visão acerca da história da arte, Georges Didi-Huberman em La imagen superviviente chama de salto. $\mathrm{O}$ que $\mathrm{o}$ atlas Mnemosine era para Warburg, segundo o autor, "uma maneira de ter em mãos toda uma multiplicidade de imagens, uma ferramenta prática para saltar facilmente de uma a outra." (DIDIHUBERMAN, p. 426). Neste capítulo do livro, chamado Montagem Mnemosine: Quadros, fusées, detalhes, intervalos, o autor começa o capítulo afirmando: "Essa forma de exposição existe" (p. 410). Em 1924, Warburg visionou que, muito mais que um resumo em imagens, o Atlas Mnemosine poderia ser um pensamento por imagens, e a partir deste ponto de vista, ele começou a construir as pranchas como uma "memória em ação" (DIDI-HUBERMAN, p.410). Afirma sobretudo que o Atlas é um dispositivo fotográfico utilizado para fazer quadros com fotografias, a palavra quadro é utilizada em dois sentidos: pictórico e, o que mais nos interessa neste ensaio, no sentido combinatório:

Mas o atlas warburguiano é 'quadro' sobretudo no sentido combinatório uma 'série de séries', como tão bem o definiu Michel Foucault -, pois cria conjuntos de imagens que coloca uma continuação em relação umas com as outras. (DIDI-HUBERMAN, p.412)

Neste sentido combinatório, Warburg age como um curador. Intencionalmente ou não, ele cria exposições em cada prancha e na relação entre elas, e como afirmou Didi-Huberman, existe essa forma de exposição, então o autor usa a palavra exposição para explicar o atlas, além disso conclui que no sentido combinatório da palavra quadro o atlas é uma montagem Mnemosine, se referindo ao título do capítulo, e dessa forma também é uma curadoria.

\footnotetext{
${ }^{5}$ As traduções contidas neste artigo foram realizadas pela autora.
} 
Sobre a qualidade de montagem que 0 atlas possui, Didi-Huberman ressalta que Mnemosine propõe algo bem diferente daquilo que se pensa sobre montagem: não é somente escolher e reunir as imagens sobre uma narrativa, mas, sim, um dispositivo fotográfico organizado de maneira complexa a fim de oferecer ao espectador uma maneira visual e impensada de encontrar a memória da história, pertencente a um anacronismo fundamental: a memória da história é decifrada através de um jogo anacrônico visual.

É evidente que não se supõe montagem como procedimento quando Warburg construiu seu atlas, como o fez Georges Braque, como compara o autor: "Não é somente uma maneira de fabricar o objeto o que nos impõe a ver em Mnemosine uma aposta na prática da montagem: é, sobretudo, o paradigma mesmo do pensamento que o sustenta e do conhecimento que dele resulta." (DIDIHUBERMAN, p. 437)

Este paradigma do pensamento é o movimento dialético que as relações entre as imagens produzem, sobretudo, no tempo. O tempo é pensado, segundo o autor, como uma montagem de elementos heterogêneos, nos remete a pensar o passado através de saltos temporais e de significado, e não somente ver o passado, ou menos ainda excluir o passado, afirmando por final a atualidade do Mnemosine ${ }^{6}$.

Sabendo agora que o atlas é uma forma de exposição, é uma montagem e pensada em quadros como uma montagem combinatória, e que essa combinação, que é anacrônica, é possível porque Warburg pensa imagem como símbolo e significante em um intervalo, seja cultural entre a história e a antropologia, por exemplo, podemos pensar este processo do pensamento por imagens e das escolhas dessas imagens como uma curadoria. Empregamos assim um termo mais recente - curadoria - para entendermos o atlas como uma exposição com um pensamento curatorial que eliminava barreiras geográficas, culturais, temporais, como exemplo: uma medalha antiga com um selo de correios.

\footnotetext{
6 “Mnemosine é um objeto sem idade”. op. cit., p.438.
} 


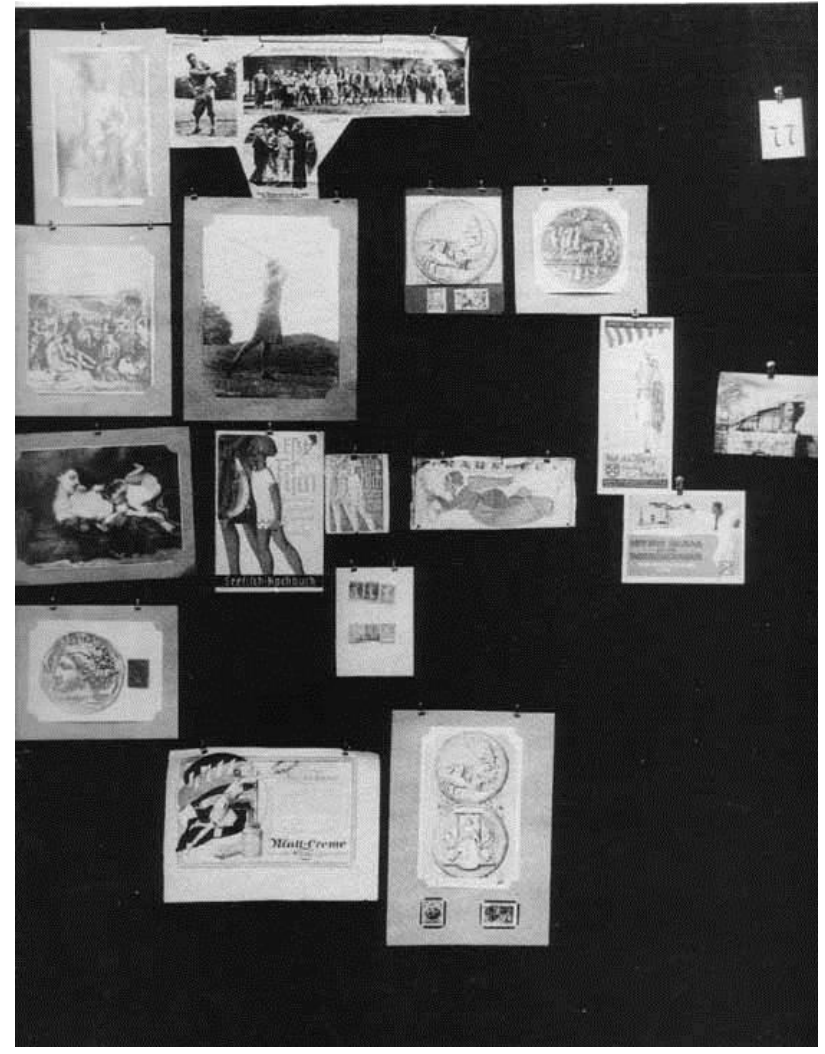

Aby Warburg, Mnemosine. Prancha 77. 1929

Quando alguém observa pela primeira vez o atlas é quase impossível saber exatamente em que direção Warburg quis orientar nossa visão ou ainda de que significante exato trata tal prancha na relação das imagens próximas. Quanto mais se olha, se observa, mais densas e intrincadas parecem tais relações, segundo DidiHuberman, que afirma ainda que mais que oferecer uma interpretação preexistente, as pranchas do atlas oferecem uma matriz visual para multiplicar suas maneiras possíveis de interpretação. Tal como uma exposição que, além da curadoria pensada para ela, ainda é possível estabelecer outras relações entre as obras apresentadas.

Desta forma, as obras são escolhidas e articuladas por um curador para a exposição da mesma maneira. O curador, talvez inconscientemente, também enxerga as obras de arte que escolhe para uma exposição como aquelas que têm cargas emotivas aliadas às formais, porque assim é possível pensá-las como símbolos de maneira mais abrangente e então haver intervalos com a possibilidade de estabelecer as relações, as conexões que enxergamos ou multiplicamos quando 
observamos uma exposição. No catálogo do $31^{\circ}$ Panorama da Arte Brasileira ${ }^{7}$, Adriano Pedrosa nos dá pistas sobre os significantes de sua curadoria:

O resultado foi uma mostra composta por obras brasileiras feitas por estrangeiros, nem tanto com elementos exóticos, mas através de uma forte presença da abstração geométrica na qual a grade é muitas vezes substituída por elementos orgânicos, sinalizando um legado do neoconcretismo. (PEDROSA, 2010)

É de interesse pensar que o Panorama de 2009 possa ser comparado ao Atlas Mnemosine no momento que há também uma montagem de obras de épocas, culturas e países diferentes tratando de um mesmo tema, instaladas de acordo com tal significante em comum. Ao relacionar tais obras no espaço expositivo estamos estabelecendo um pensamento por imagens e estamos transcendendo as fronteiras geográficas, temporais e culturais, graças às escolhas do curador.

Portanto, as obras estão inseridas em um contexto de significante mais abrangente do que simplesmente o pode ser a arte brasileira vista por estrangeiros, ou ainda qualquer outro significante que a gente possa interpretar. As obras tratam de referências diferentes de arte brasileira, elaboradas com materiais e contextos culturais diversos, mas que se relacionam neste espaço, eliminando assim fronteiras culturais, temporais e geográficas, e apontando um mesmo significante, a saber, o discurso curatorial.

Neste contexto, o $31^{\circ}$ Panorama reuniu obras de artistas estrangeiros que de algum modo tenham se engajado com a arte, com a cultura ou com a história brasileira. Num sentido expandido, 'arte brasileira' é aqui compreendida não como arte produzida por brasileiros, mas como aquela que estabelece fortes referências a temas e conteúdos brasileiros. (PEDROSA, 2010)

\footnotetext{
7 MUSEU DE ARTE MODERNA DE SÃO PAULO (instituição). Panorama da Arte Brasileira 2009. Mamõyguara Opá Mamõ Pupé. Curadoria: Adriano Pedrosa. São Paulo: mam, 2010. Catálogo de Exposição
} 
De fato, longe de forçar a comparação, estamos diante de uma possibilidade de relacionar um pensamento curatorial específico - aquele criado por Adriano Pedrosa para o Panorama 2009 - com as elaborações de pensamento por imagens construídas por Warburg no Atlas Mnemosine.

A possibilidade surgiu quando, na eliminação das fronteiras culturais, geográficas e temporais proposta por Pedrosa ao escolher os artistas estrangeiros, remeteu-se ao atlas, pois, neste último, há também a proposta de eliminar tais barreiras, mas, a comparação vai muito além porque Warburg de fato montou uma forma de exposição ao construir as pranchas, e nelas um pensamento por imagens, ou seja, uma curadoria, no sentido mais amplo e anacrônico que seja possível.

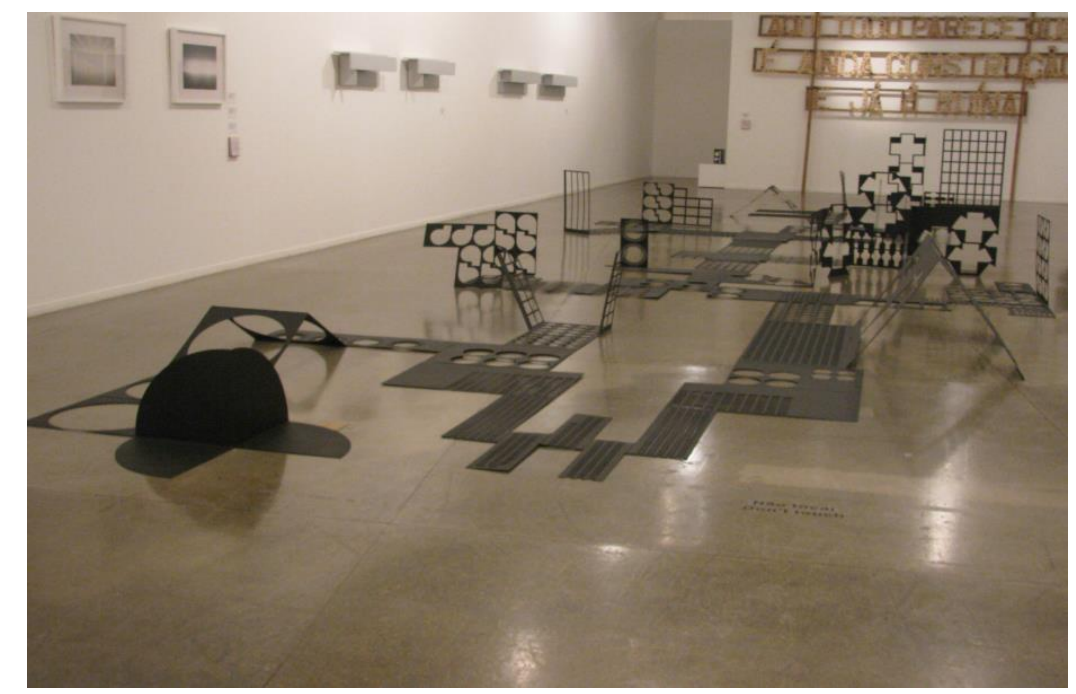

Vista parcial do $31^{\circ}$ Panorama da Arte Brasileira. Nota-se quatro obras de período de realização e período de referência à arte brasileira distintos, assim como artistas de diferentes países, montadas na mesma sala, estabelecendo relações entre elas, com o mesmo significante em comum: o discurso curatorial. 